\title{
Uso do webfólio como instrumento avaliativo da aprendizagem em Física: reflexões formativas
}

\author{
Sebastião Rodrigues-Moura \\ Alexandre Guimarães Rodrigues \\ Licurgo Peixoto de Brito
}

\section{Resumo}

Este artigo apresenta os resultados de uma pesquisa mais ampla desenvolvida em uma turma do ensino médio, de uma escola pública do estado do Pará, Brasil, para a qual aplicamos atividades diversificadas sobre o ensino de física com vistas à aprendizagem de temas modernos e contemporâneos da ciência. A prática de intervenção foi por meio da implementação de uma sequência didática na qual o uso de ferramentas de avaliação da aprendizagem foi estruturado de webfólios. Em vista disso, objetivamos analisar aspectos de desenvolvimento da aprendizagem por meio do uso de webfólios como instrumento avaliativo em Física a partir da implementação de uma intervenção pedagógica com atividades diferenciadas no ensino médio. Em sua abordagem a pesquisa tem caráter qualitativo e pudemos observar a realidade e as possibilidades no uso dos webfólios como base de construção de conhecimento científico para que estudante discorra e se posicione sobre determinado assunto, desenvolva sua autonomia frente ao conhecimento, torne-se mais ativo e participativo no processo, bem como utilize mecanismos de aprendizagem para sua inserção social. Por fim, destacamos que os resultados apresentados incorporam o que a literatura defende do processo avaliativo e conduz o estudante ao seu protagonismo enquanto cidadão.

Palavras-chave: Ensino de Física; Ferramentas de avaliação; Webfólios. 


\title{
Use of the web-portfolio as evaluative instrument of learning in Physics: formative reflections
}

\author{
Sebastião Rodrigues-Moura \\ Alexandre Guimarães Rodrigues \\ Licurgo Peixoto de Brito
}

\section{Abstract}

This article presents the results of a broader research developed in a class of high school, from a public schools in the state of Pará, Brazil, for which we apply diversified activities on the teaching of physics with a view to learning themes Modern and Contemporary Physics. The practice of intervention was through the implementation of a didactic sequence in which the use of learning assessment tools was structured by web-portfolios. In view of this, we aimed to analyze aspects of learning development through the use of webportfolios as an evaluative instrument in physics from the implementation of a pedagogical intervention with differentiated activities in high school. In its approach, the research has a qualitative nature and we were able to observe the reality and possibilities in the use of the web-portfolios as a basis for constructing scientific knowledge for students to discuss and position themselves on a certain subject, develop their autonomy in the face of knowledge, become more active and participative in the process, as well as use learning mechanisms for their social insertion. Finally, we emphasize that the results presented incorporate what the literature defends from the evaluative process and leads the student to its protagonism as a citizen.

Keywords: Physics teaching; Evaluation tools; Web-portfolios. 


\section{Palavras Introdutórias}

Como avaliar satisfatoriamente a aprendizagem dos estudantes no processo de ensino e aprendizagem da Física no percurso do ensino médio? Esta indagação inicial nos parece que sempre foi um percalço para o professor para a compreensão da sua prática pedagógica, de planejamento didático, de concepção para a apreensão do conhecimento, de horizonte para se prospectar o processo educacional com um papel mais dinâmico, eficaz e autônomo para os sujeitos envolvidos.

Hoffman (2005; 2007) e Luckesi (1997) concebem a avaliação como resultado de um processo de mediação pedagógica e formativa da dinâmica escolar, com a intenção de buscar mecanismos favoráveis do acompanhamento contínuo e evolutivo da aprendizagem dos estudantes e da ação sobre a prática. Para a avaliação no ensino de Física, Rosa (2011) nos aponta que esse processo sempre pareceu doloroso, dada as altas taxas de reprovações do âmbito do ensino médio, o que representa um dos percalços da formação dos estudantes sobre a ciência e, de certa forma, os distancia da compreensão da ciência como construção humana.

Cientes dos obstáculos que permeiam as dificuldades da aprendizagem dos estudantes sobre a prática do professor, é que propomos essa discussão analítico-prática sobre o uso de um instrumento avaliativo - o webfólio - aplicado a uma turma de ensino médio com vistas à dinamização da avaliação formativa dos estudantes em Física. Além disso, voltamos nossos olhares para o professor, o sujeito que desde a sua formação inicial, ainda inquieta-se sobre como avaliar o estudante de modo mais adequado possível, sem prejuízos ao processo educacional.

Ancoramos a nossa investigação em uma questão balizadora para aqui justificarmos o nosso objeto de estudo na forma de compreender que elementos de desenvolvimento aprendizagem discente são observadas no processo de avaliação em Física por meio do uso de webfólios no ensino médio? Dessa forma, outras questões nos parecem ancorar esta primeira para visualizarmos como esse processo se dá: (i) o que são webfólios e para que servem?; (ii) como oportunizar o uso de webfólios em aulas de Física; (iii) o que esse instrumento propicia à aprendizagem dos estudantes?; e, (iv) existe um modelo padrão de webfólio para sua aplicação prática?

Do exposto, ocupamo-nos neste artigo, parte de uma pesquisa mais ampla sobre o processo de ensino e aprendizagem em Física, em analisar aspectos de desenvolvimento da aprendizagem por meio do uso de webfólios como instrumento avaliativo em Física a partir da implementação de uma intervenção pedagógica com atividades diferenciadas no ensino médio. A pesquisa possui abordagem qualitativa e os resultados aqui apresentados são dados norteadores para o professor refletir sobre a sua prática, acerca de como avaliar o estudante e, sobretudo, de ponderar sua postura didático-pedagógica sobre o seu papel formativo. 


\section{Uso de webfólios no processo de avaliação dos estudantes no ensino médio: o que a literatura já nos sinaliza?}

Diante do processo evolutivo do uso das tecnologias em sala de aula, tratar de estratégias diversificadas e ferramentas avaliativas não nos parece "modismo" quando a aprendizagem protagoniza o cenário principal na formação humana dos estudantes. É nesse sentido que muitos processos, métodos, ferramentas e outros mecanismos emergem na escola, dando oportunidade ao professor para diversificar sua práxis e aos estudantes são ofertadas situações que lhes dão autonomia para a construção e ampliação do conhecimento científico.

Nesse contexto de métodos e estratégias de avaliação, surge o webfólio como uma ferramenta tecnológica, no qual o professor assume um papel importante na mediação pedagógica do conhecimento científico e insere o estudante em um espaço de participação ativa, autônoma e de reflexão para o seu desenvolvimento pessoal e profissional. O webfólio nos leva a repensar o portfólio, como um espaço com textos, imagens, documentos e evidências de quem elabora argumentos para dar continuidade à sua aprendizagem, como nos aponta Hernandez (2000), haja vista que o primeiro é similar ao segundo, mas agora em uma versão eletrônica, interativa, com maior socialização da produção científica e de fácil atualização, tal como nos esclarece Grace e Shores (2001).

Alguns autores definem o webfólio como "e-portfolio", "portfólio digital”, "blogfolio" e "webfolio", porém, apesar da variação de nomenclatura, a forma de uso possui a mesma finalidade. Historicamente, Nevaldo, Basso e Menezes (2000) destacam que essa ferramenta vem sendo utilizada desde 1996 na Universidade Federal do Rio Grande do Sul em um ambiente virtual de aprendizagem, mais especificamente no Laboratório de Estudos Cognitivos (LEC/UFRGS), com posterior disseminação, porém não se sabe exatamente onde surgiu e quem o projetou, mas que, de toda forma, o seu uso vem ganhando espaço tanto na educação básica como no ensino superior para o desenvolvimento da aprendizagem dos estudantes.

Alves (2006) nos apresenta uma visão mais ampla sobre essa discussão, trazendo alguns elementos de compreensão sobre o uso destas ferramentas, conforme suas finalidades, a saber

a) Porta-fólio - como é chamado no Canadá, significa uma amostra do dossiê. É o recipiente ou pasta onde se guardam todos os materiais produzidos pelo estudante, cronologicamente.

b) Processo-fólio - visto como instrumento que reflete a crença de que os estudantes aprendem melhor e de uma forma mais integral, a partir de um compromisso com as atividades ocorridas durante um período de tempo significativo que se constrói sobre conexões naturais com os conhecimentos escolares.

c) Webfolios - com os avanços da tecnologia da informação e comunicação, os webfólios podem guardar toda a memória do período escolar desde a educação básica até a educação superior de um estudante, memória que 
servirá como processo de reconstrução de suas aprendizagens e como elemento de avaliação (ALVES, 2006, p. 104-105).

Nesse sentido, os autores citados anteriormente, ao voltarem suas discussões para a avaliação da aprendizagem, apontam que os webfólios

\begin{abstract}
constituem-se em "espaços" privilegiados de registro dos processos e produtos da aprendizagem num determinado contexto. Mesmo não havendo uma unanimidade quanto a sua função, organização ou composição, basta uma breve revisão da literatura para identificar uma tendência de concepção dos webfólio como uma espécie de "dossiê" que privilegia as melhores produções dos sujeitos. Se tomamos a perspectiva de avaliação "na" aprendizagem, recusaremos o modelo de webfólio que apresenta apenas os melhores trabalhos ou as melhores performances do sujeito, mas valorizaremos e até mesmo enfatizaremos os ensaios de trabalhos inacabados, rascunhos, reflexões, diários de bordo, pesquisas de campo etc. (NEVALDO, BASSO e MENEZES, 2004, p. 300, grifos nossos)
\end{abstract}

Para além do exposto, grafamos elementos indispensáveis para associar os webfólios como meio de aprendizagem colaborativa, de produção de conhecimentos, de formação de sujeitos, bem como de avaliar a aprendizagem em suas diversas formas, seja a partir dos "melhores trabalhos" ou daqueles que precisam ser melhores lapidados e orientados para a reflexão. É nesse âmbito, que observamos o potencial uso dessa ferramenta como mecanismo de aprendizagem no ensino de ciências e, em especial, no ensino de Física no percurso do ensino médio. Alinhado a essa discussão, Mercado (2008) apresenta o webfólio como um

conjunto de registros das trajetórias, processos e produtos das aprendizagens no ambiente virtual; coletânea de trabalhos realizados e selecionados pelo educando, auxiliando-o a desenvolver a capacidade de se auto-avaliar. Ao professor oferece a oportunidade de traçar referenciais para o grupo. No webfólio valorizam-se todas as etapas, mesmos inacabadas, do processo de busca e investigação que os alunos realizam, do mesmo modo que as impressões, opiniões e sentimentos despertados pelo assunto em pauta ou até pela forma de trabalho, questionamentos aos encaminhamentos dados e assim por diante (p. 5, grifos nossos)

É no sentido de inspirar nossos leitores que buscamos elencar o potencial dessa ferramenta na mediação pedagógica, para se entender o processo de ensino-aprendizagem como "construção" e não como "pronto e acabado". Mercado (2008) ainda complementa que o uso do webfólio articula o que o estudante pretende no curso e na sua formação, traça conexões com suas vivências e experiências de vida, pode retomar assuntos, conteúdos e problemas ainda não resolvidos em sociedade, aumenta seu nível de confiança, de (auto)estima e de tomada de decisão social. Para a construção do webfólio, Ferraz, Ferreira e Gomes (20013) destacam que “...na construção do seu webfolio, o estudante é responsável por organizar o seu processo de aprendizagem, podendo e devendo tomar iniciativas e definir e alterar estratégias ISSN 2526-2882

$$
* 108 *
$$


em função do que achar mais adequado, de modo a desenvolver as suas aprendizagens.” (p. 6602)

Nessa discussão que Villas Boas (2006) retoma a discussão da autonomia discente como estímulo e tomada de decisão sobre a sua realidade e suas experiências de vida e Miranda (2017) discorre sobre sentidos, significados e desafios sobre o uso dessa ferramenta, haja vista que

a construção de webfólios cria a possibilidade de espaços de aprendizagens diversos, pois ultrapassa o modelo escolar vigente, no qual todas as prescrições são dadas quase que exclusivamente em sala de aula e pelo professor. Nessa perspectiva, o estudante, ao criar o seu webfólio, organiza o seu desenvolvimento intelectual, reflete sobre o seu próprio aprendizado, faz uma revisão constante sobre o que já postou e envolve-se ativamente em suas aprendizagens (p.279)

Por fim, Sá-Chaves (2005) destaca que o webfólio é uma atividade desenvolvida sob a orientação do professor em parceria com grupos de estudantes a fim de ser um meio de articulação entre professor - conhecimento - estudantes mediados pela reflexão e, sobretudo, um feedback para aquisição do conhecimento dos estudantes sobre o estudo de física de partículas e outras discussões pertinentes.

\section{Percursos metodológicos da pesquisa}

A presente pesquisa possui abordagem qualitativa, quanto à natureza, e exploratória quanto aos objetivos, para a qual traremos uma discussão analítica sobre o uso de webfólios como instrumentos para avaliação para a aprendizagem em Física. Com vistas a esses elementos da pesquisa, a opção pelo tratamento dos dados de forma qualitativa é por nos inspirar nos trabalhos de Gerhardt \& Silveira (2009) e Triviños (1987) que as definem a partir do olhar sensível dos pesquisadores sobre o objeto de estudo.

Ao trazermos elementos qualitativos para esta pesquisa, voltamos nossos olhares sobre as diversas variáveis que emergem quando buscamos mecanismos de compreensão sobre a prática e na busca de possíveis respostas às inquietações pessoais e profissionais sobre a concepção do processo escolar. Além disso, enfatizamos que o caráter empírico do objeto de estudo nos prima pela qualidade da pesquisa, a cientificidade acerca do tema central e o uso adequado dos instrumentos que consideramos factíveis para a destacar os elementos quanto à questão de investigação.

A opção pela pesquisa explicativa emerge diante da nossa situação em identificar e situar os nossos leitores quanto aos fatores que emergem do fenômeno investigado, de modo a elencarmos aqueles que determinam e dão maior embasamento aos resultados expostos. Apesar de parecer descritiva também, daremos maior ênfase no caráter explicativo trazendo a 
realidade e as possibilidades que tornam o objeto de investigação suficientemente eficaz no processo de ensino e aprendizagem da Física.

No contexto da realidade e das possibilidades, adotamos como categorias analíticas para as quais os resultados serão apresentados e discutidos de forma a não esgotar as referências acerca do objeto de estudo. Ao analisar elementos da realidade e das possibilidades, adotamos tais categorias em um par dialético proposto por Cheptulin (2004), para o qual a realidade é o que de fato existe, o que ocorre, por meio de ações interventivas e as possibilidades são situações que podem ocorrer no processo quando as condições são favoráveis. Dessa forma, o que são possibilidades explicativas, em um momento posterior em caso de situação propicia de ocorrência vem a tornar-se a realidade a ser vivenciada.

É importante destacarmos aqui que a proposta de intervenção pedagógica foi aplicada a um grupo de estudantes do ensino médio, de uma escola pública localizada no nordeste estado do Pará, região amazônica brasileira. A realidade da escola ainda um pouco distante de escolas desenvolvidas e equipadas com instrumentos tecnológicos e digitais, mas como um espaço de laboratório de informática não nos deixou intervir sobre a prática, utilizando o mínimo do que temos, como um meio de crermos no que temos e daquilo que podemos ensejar para melhorias sobre o ensino e a aprendizagem do estudantes, tal como muitos estabelecimentos de ensino no Brasil, quiçá alguns que nem possuem o mínimo dessa infraestrutura educacional, mas que não deve ser motivo de desânimo para a educação dos nossos cidadãos.

\section{Resultados e discussões}

A partir deste momento, ocupamo-nos em analisar e discutir os dados de nossa investigação para o qual os argumentos apresentados terão em sua base científica o papel de fortalecimento sobre a práxis pedagógica. É nesse intuito que, enquanto pesquisadores em educação em ciências, compreendemos que a adoção do materialismo dialético de Cheptulin (2004) nos posiciona sob uma análise de múltiplos olhares acerca do que fazemos na nossa prática e daquilo que, por meio de aprimoramento do percurso, pode a vir a transformar a realidade e potencializar a ação sobre a relação mediadora entre estudantes-conhecimentoprofessor.

\section{(i) A realidade dos webfólios como instrumentos de avaliação na prática}

Enquanto realidade, é importante deixar claro que o uso dos webfólios deu-se a partir da implementação de sequência didática sobre física de partículas, desenhada em seis lições ${ }^{18}$

18 O termo "lição" refere-se aos encontros didáticos propostos na sequência didática. Este produto está acompanhado de um guia didático, estão dispostos em sua íntegra como apêndice da pesquisa para consulta e utilização no material produzido por Rodrigues-Moura (2016). 
e, para cada lição, um webfólio era produzido como meio contínuo de construção do conhecimento científico.

Tomamos como prioridade a apropriação da ideia de os estudantes produzirem webfólios sob a orientação do professor acerca do estudo proposto, dentro das perspectivas dos conteúdos a serem explorados e serem postados em um blogue educativo ${ }^{19}$, no qual foram inseridos os webfólios produzidos pelos estudantes, como meio essencial de discussão entre os estudantes e publicação das questões para reflexão acerca dos questionamentos presentes nas lições, considerados bastante flexíveis de modo a aceitar novas indagações a serem propostas.

No blogue foram postadas as respostas que os estudantes desenvolveram acerca dos questionamentos abertos propostos nas lições da sequência didática, a partir da construção dos webfólios, sempre flexíveis a novas indagações. É crucial destacar que a escolha de perguntas a serem respondidas por lição pelas equipes de estudantes foi de responsabilidade integral dos mesmos, o que reforça o caráter de autonomia visado inicialmente na proposta. Os estudantes foram orientados para que as perguntas a comporem os webfólios de cada equipe não deveriam ficar restritas às contidas nas lições, podendo ir para além do conhecimento contido no material didático. Esquematizamos um design de construção de webfólio esboçado na Figura 1, como modelo de instrumento para avaliação da aprendizagem.

Figura 1: Modelo para construção de webfólio

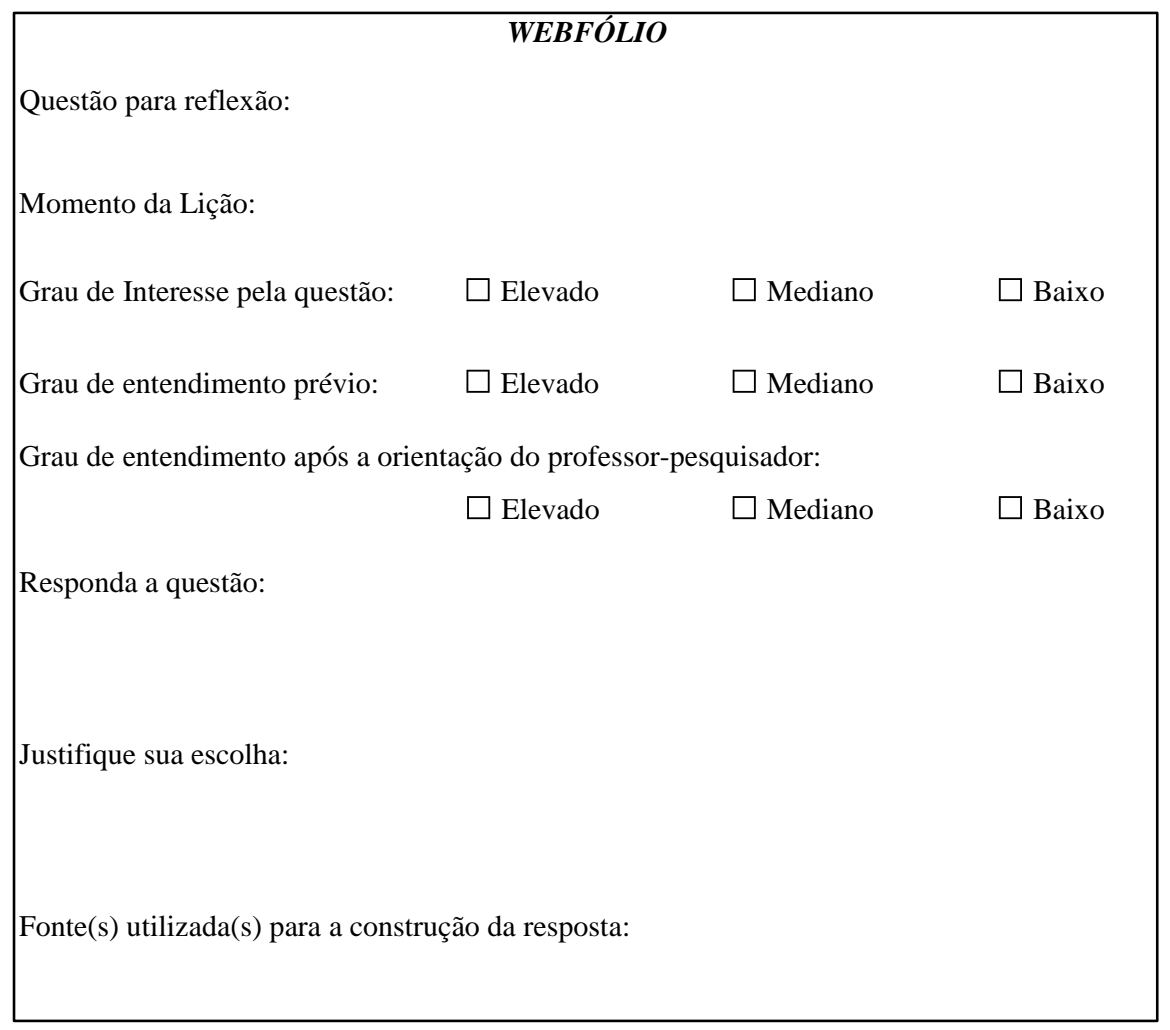

Fonte: Com inspiração em Rodrigues (2015)

19 O blogue desenvolvido pelos estudantes encontra-se disponível no link http://elementaisdafisica.blogspot.com 
Os elementos do webfólios possuem um grau de aplicação amplo quanto ao que o estudante pode desenvolver e se torna um mecanismo de devolutiva do processo de ensino ao professor, como mecanismo de compreensão da apropriação e da evolução da aprendizagem dos estudantes. Itens como o grau de interesse pela questão, de entendimento prévio, de entendiemento após a orientação do professor nos trazem elementos da ação pedagógica e de reflexão sobre a prática. É nesse intuito que o olhar do professor sobre o andamento do processo de construção dos webfólios deve ser estruturado e organizado, primando não só pela sua conclusão e publicação, mas de forma a entender como todo o processo.

Os pontos e contrapontos explícitos no modelo para construção de webfólio constantes da figura 1 são relevantes e estarem associados ao fato de ser de fácil compreensão, manuseio e, sobretudo, por "permitir que os usuários publiquem seus conteúdos sem a necessidade de saber como são construídas páginas na internet; ou seja, sem conhecimento técnico especializado" (RODRIGUES, 2008, p.49). Recomenda-se que na própria escola sejam feitos o uso de um laboratório de informática e de outros espaços acesso ao blogue, visando essa facilidade de elaboração dos webfólios e posterior postagem, de modo a atender aqueles que, porventura, não tenham acesso à internet em suas casas.

Frente ao modelo proposto, teceremos aqui algumas inferências acerca da prática do uso do instrumento, de modo a não nos determos sobre o que foram produzidos pelos estudantes, mas trazermos o potencial atribuído à aprendizagem. A vertente exposta na discussão não serão aqui esgotadas quanto ao que os estudantes produziram, mas no que se concebeu na prática. Relacionado à realidade vivenciada, alguns elementos são explicados para uma consolidação da compreensão sobre o uso dos webfólios enquanto intrumentos de avaliação da aprendizagem, a saber:

a) O desenvolvimento da autonomia dos estudantes no processo de construção dos webfólios torna-se um dos quais nos detemos com mais afinco, por sabermos que o estudante, em seu percurso formativo, demora a apropriar-se dessa estratégia, dado o seu amadurecimento de forma gradual. O potencial uso dos webfólios deixa o estudante mais livre às suas escolhas e persistente à construção de conhecimento científico, emergindo dessa forma uma autonomia necessária à apreensao dos saberes de forma coesa e adequada;

b) O engajamento na construção de conhecimento nos é demonstrado, apesar de ser por muitos considerado subjetivo, mas ao nosso olhar apresentou-se como uma forma de concepção e de incentivo às curiosidades que surgiam dos estudantes e, ao mesmo tempo, sustentandor à qualidade instrucional dos constructos produzidos. As estratégias de melhor organização do conhecimento científico frente às atividades diversificadas são também aqui concebidas como um fator de engajamento que foi estabelecido no processo pedagógico;

c) O trabalho em equipe representou outro elemento que nos fez compreender a interatividade dos sujeitos envolvidos, de modo a propiciar a discussão sobre a ciência, sobre 
como melhor construir uma resposta, onde localizar informações fiéis ao que a comunidade científica produz e, de todo modo, como meio de materializar a dialética socialmente constituída para integrar a aprendizagem. O trabalho em equipe é um elemento potencial para a construção do sujeito em sociedade, frente às diversidades de pensamentos, opiniões e diferenças metacognitivas existentes no contexto real de sala de aula e, posterior generalização em sociedade.

d) O feedback pedagógico é resultado da interação mediada pelo professor e o estudante acerca do conhecimento, uma vez que muitos professores ainda não conseguem ter esse retorno sobre o que é feito e sua ação ainda permenece permeada de dúvidas, anseios e inquietações. O feedback propicia ao professor entender sua prática, a sua dinâmica de avaliação sobre os estudantes e, de uma forma mais próxima da sua realidade, buscar mecanismos que fortalecam e dinamizem o espaço escolar como meio de múltiplas aprendizagens.

Os quatro elementos explicados acima não inserem um ponto final sobre a realidade do que se pode estabelecer quando o uso dos webfólios são inseridos em aulas de Física, mas como um instrumento que tem variadas funções sobre a aprendizagem a fim de possibilitar ao professor e aos estudantes lançarem-se à frente com novas perspectivas de projeção sobre o conhecimento científico.

\section{(ii) Aspectos formativos e as possibilidades dos webfólios em aulas de Física}

Para além dos elementos descritos e explicados no item (i) dos resultados desta pesquisa, vamos projetar as variadas possibilidades pedagógicas e instrumentais que a construção do webfólio viabilizam tanto aos estudantes quanto ao professor, tidos aqui como sujeitos em constantes transformações e abertos a novas experiências para pensar sobre a própria formação.

Dentre as possibilidades a serem elencadas e explicadas a seguir, nos detemos sobre aspectos formativos para os quais temos convicção de que o seu uso potencializa as aulas de Física e a formação para a cidadania, tais como:

a) conduzir os estudantes ao desenvolvimento e ampliação de sua atonomia, uma vez que ainda muito raro, os estduantes estão "presos" em um sistema no qual "enxergam" os professores como sabedor e detentor do conhecimento científico, ao passo que o mundo globalizado e interativo permite ao estudante desenvolver-se, pesquisar e buscar forma de apreensão da ciência e de sua produção para ampliar sua visão de mundo e de sociedade;

b) permitir a tomada de decisão sobre a sua prática como elementos de o estudante protagonizar e entender a inter-relação a produção da ciência, o desenvolvimento tecnológico e as implicações sociais inerentes a esse processo. Tal qual se estabelece e entende-se essa 
tomada de decisão como um meio de os estudantes compreenderem melhor a sua realidade e buscar invervir sobre a mesma;

c) estabelecer a formação para a cidadania, entendida quanto o sujeito como parte do processo social e o uso de webfólios permite que os estudantes comecem a traçar sua formação, trazer reflexões sobre a sua vida, do seu bairro, da sua cidade, partindo para uma visão mais geral e, sobretudo, compreendendo a sua formação como processo de construção social;

d) associar a ciência como uma produção histórica da humanidade, haja vista que tudo é um processo e essa possibilidade alinha a aprendizagem como um meio de entender como a ciência se desenvolve, o processo do método científico e suas tranformações, bem como enxergar o homem como o precursor da história da ciência, sua natureza, suas intervenções, suas práticas e seu constructo social;

e) buscar a interatividade, socialização e divulgação científica como elementos primordiais para ampliar a discussão sobre ciência e tecnologia e, de uma forma eletrônica, disseminar o conhecimento produzido como estratégia de emancipação e interação com o se conhece, estabelecida uma associação de saberes e tessituras de reflexões sobre a ciência; e,

f) transformar socialmente a sua realidade, como forma de sair de um espaço passivo da sala de aula e ir a campo, extender o seu conhecimento científico produzido à sociedade, pois esta aguarda incansavelmente as construições do conhecimento produzidos nos estabelecimentos de estudos e pesquisas para que haja uma tranformação com vistas ao bemestar dos cidadãos.

É nesse sentido de possibilidades, que aqui não se esgotam, que o uso de webfólios traz como referência ao uso de recursos digitais na sala de aula e busca minimizar as barreiras existentes de exclusão social digital. Com isso, os estudantes podem criar divresos mecanismos de aprendizagem a partir da sistematização de suas ideias e organizá-las em formatos de textos, imagens, vídeos, links e outras informações que permitiram interagir com a linguagem e letramento digital de outros estudantes e da sociedade de uma forma mais geral.

\section{Tecendo algumas considerações}

Objetivamos neste artigo, tecer reflexões formativas sobre o uso de webfólios como instrumento de avaliação do processo de aprendizagem em Física no ensino médio. Trata-se uma proposta desenvolvida e utilizada como mecanismo de compreensão da construção de conhecimentos científicos a partir de uma intervenção pedagógica no percurso final da educação básica no contexto de uma escola pública na região amazônica brasileira, com todos os seus trações e contrastes socioeconômicos.

Vislumbrando ampliar essa discussão para a aprendizagem, tomamos como base o materialismo dialético proposto por Cheptulin (2004) para traçarmos elementos da realidade vivenciada e das possibilidades que podemos propor frente ao uso dos webfólios para a 
aprendizagem em ciências. Dessa forma, primamos por trazer uma análise discursiva e argumentativa sobre alguns aspectos de desenvolvimento da aprendizagem identificados por meio do uso de webfólios como instrumento avaliativo em Física a partir da intervenção pedagógica com atividades diferenciadas no contexto do ensino médio.

Quanto à realidade apresentada, observamos que os estudantes puderam obter autonomia da aprendizagem, engajamento na produção do conhecimento científico, trabalho colaborativo em equipe e, sobretudo, um feedback pedagógico, entendido como resultado da mediação pedagógica existente na relação estudante-conhecimento-professor. Dessa forma, notamos que esses elementos didáticos são cruciais para se estabelecer uma consolidação da aprendizagem no ensino de ciências, especificamente em Física, estabelecendo um estreito alinhamento da dinâmica do processo educacional e, de certa forma, coloca-se o estudante como protagonista do conhecimento científico e sua ação sobre a prática.

Para além da realidade observada, tecemos algumas reflexões como possibilidades a serem desenvolvidas nos estudantes e na prática pedagógica tais como a ampliação da autonomia discente, a tomada de decisão sobre a prática como meio de inserção e transformação social, alinhada à formação para a cidadania, por meio de uma interconexão interativa da divulgação científica e a compreensão da ciência como produto socialhumanístico. É no sentido das possibilidades que abrimos amplitude para que nossos professores e estudantes criem e desenvolvam com mais afinco a responsabilidade sobre a produção científica, a divulgação social da ciência e, principalmente, a transformação social dos sujeitos.

A partir da tessitura das reflexões apresentadas, observamos que a realidade e as possibilidades são mais amplas do que o objetivo educacional do ensinar e apreender ciências, uma vez que o homem enquanto sujeito socialmente estabelecido é capaz de transformar a sua prática e desenvolver possibilidades de avanços e perspectivas para o processo da aprendizagem. Destacamos, por fim, que o uso dos webfólios não seja só mais um instrumento que venha a ser utilizado em sala de aula, como forma de "inovar" a aula, mas como processo de motivação para se entender as aulas de ciências como dinâmicas, motivadoras para o campo social e suas implicações.

Em linhas conclusivas, a realidade e as possibilidades apresentadas como resultados obtidos coadunam de maneira mais geral com o objetivo proposto e a problemática apresentada, por trazer elementos que são aqui considerados indícios para o desenvolvimento da aprendizagem discente e podem ser trabalhadas e observadas junto ao processo de avaliação em Ciências/Física a partir do uso de webfólio no ensino médio. Portanto, asseguramos que os webfólios representam a construção do conhecimento dos estudantes acerca de questões que consideram relevantes no ensino de Física, reúne e agrupa dados, bem como as informações necessárias para que possa identificar o desempenho dos estudantes conforme a proposta 
didática, garantindo a aprendizagem adequada e possibilidade ao professor refletir sobre a sua própria prática.

\section{Referências}

ALVES, L. P.. Portfólios como instrumentos de avaliação dos processos de ensinagem. In: ANASTASIOU, Léa das Graças Camargos; ALVES, Leonir Pessate (Orgs.). Processos de ensinagem na universidade: pressupostos para as estratégias de trabalho em aula. 6.ed. Joinville, SC: UNIVILLE, 2006, 101-120.

CHePtulin, A.. A dialética materialista: categorias e leis da dialética. São Paulo: AlfaÔmega, 2004.

GERHARDT, T E; SILVEIRA, D T (Orgs.) Métodos de pesquisa. Porto Alegre: Editora da UFRGS, 2009.

GRACE, C; SHORES, E. Manual de portfólio: um guia passo a passo para o professor. Porto Alegre: Artes Médicas, 2001.

HERNANDEZ, F. Cultura visual, mudança educativa e projeto de trabalho. Porto Alegre: Artmed, 2000.

HOFFMANN, J. Pontos e contrapontos: do pensar ao agir em avaliação. 9. ed. Porto Alegre: Mediação, 2005.

HOFFMANN, J.. O jogo do contrário em avaliação. Porto Alegre: Mediação, 2007.

LUCKESI, C. C.. Avaliação da aprendizagem escolar. 6. ed. São Paulo: Cortez, 1997.

MERCADO, L. P. L.. Ferramentas de avaliação na educação online. In: IX Congresso

Iberoamericano de Informática Educativa. ANAIS. Caracas, Venezuela: RIBIE - Rede Iberoamericana de Informática Educativa do Programa CYTED, 2008. Disponível em http://www.ufrgs.br/niee/eventos/RIBIE/2008/pdf/ferramientas_avaluacion.pdf. Acesso em 15 de janeiro de 2019.

MIRANDA, J. dos R.. O Webfólio como procedimento avaliativo no processo de aprendizagens: sentidos, significados e desafios. Informática na Educação: teoria \& prática, 20(2), 272-286, 2017.

NEVADO, R. A. de; BASSO, M. V.; MENEZES, C. S. de. Webfólio: uma proposta para avaliação na aprendizagem, conceitos, estudos de casos e suporte computacional. In: XV SIMPÓSIO BRASILEIRO DE INFORMÁTICA NA EDUCAÇÃO (SBI). 2004. Amazonas. ANAIS. São Paulo: SBIE, 2004. p. 299-308. Disponível em http://www.br-ie.org/pub/index.php/sbie/article/view/331/317. Acesso em 15 de janeiro de 2019. 
RODRIGUES, C.. O uso de blogs como estratégia motivadora para o ensino de escrita na escola. Dissertação de Mestrado, Universidade Estadual de Campinas, 2008.

RODRIgueS, A. G.. Relatório de Pesquisa de Estágio Pós Doutoral: Investigações sobre Metodologias de Design Based-Research (DBR) e Produção de Sequência de Ensino-Aprendizagem (TLS) com Tópicos de Física Moderna no Contexto de Ensino Superior. Desenvolvido na Universidade São Paulo sob supervisão do Prof. Dr. Maurício Pietrocola, São Paulo, 2015.

ROSA, C. T. W. da. A metacognição e as atividades experimentais no ensino de Física. Tese de Doutorado, Universidade Federal de Santa Catarina, 2011.

TRIVIÑOS, A. N. S.. Introdução à pesquisa em ciências sociais: a pesquisa qualitativa em educação. São Paulo: Atlas, 1987.

\section{Biografia Resumida}

Sebastião Rodrigues-Moura: Licenciado em Ciências Naturais com habilitação em Física (UEPA), mestre em Docência em Educação em Ciências e Matemática (UFPA) e doutorando em Educação em Ciências e Matemática (REAMEC/UFMT). Professor do Instituto Federal de Educação, Ciência e Tecnologia do Pará (IFPA) e vice-coordenador do Grupo de Estudos e Pesquisas em Rede para o Ensino de Física (GEPREF).

Lattes: http://lattes.cnpq.br/o092932409685292

Contato: sebastiao.moura@ifpa.edu.br e sebastiao.fisica@gmail.com

Alexandre Guimarães Rodrigues: Bacharel em Física (UFPA), Mestre e Doutor em Física (USP). Tem Pós-Doutorado em Informação Quântica (UFMG) e em Ensino de Física (USP). Professor do Instituto de Tecnologia da Universidade Federal do Pará (ITEC/UFPA) e coordena o PCNA, Programa de Cursos de Nivelamento de Aprendizagem para as Ciências Básicas das Engenharias, com cunho didático-pedagógico interligado à questões de ensino, pesquisa e extensão. É coordenador do grupo de pesquisa do Laboratório de Inovação Didática em Física (LIDF).

Lattes: http://lattes.cnpq.br/6167368100687689

Contato: alexgr_28@yahoo.com.br e alexgr@ufpa.br ISSN 2526-2882 
Licurgo Peixoto de Brito: Licenciado em Ciências Naturais e em Física com Doutorado em Geofísica (UFPA) e Pós-Doutor em Educação Científica e Tecnológica (UFSC). Professor do Instituto de Ciências Exatas e Naturais e do Instituto de Educação Matemática e Científica Universidade Federal do Pará (ICEN/IEMCI/UFPA) e coordena o Grupo de Estudos em Ciência, Tecnologia, Sociedade e Ambiente (GECTSA).

Lattes: http://lattes.cnpq.br/5100592138044970

Contato: licurgo.brito@gmail.com elicurgo@ufpa.br 